\title{
A metodologia Dicumba e o Aprender pela Pesquisa Centrada no Aluno no Ensino de Química: narrativas discentes na Educação Básica
}

\section{The Dicumba methodology and the Learning through Student-Centered Research at the Chemistry teaching: student narratives in Basic Education}

\author{
Everton Bedin (bedin.everton@gmail.com) \\ Programa de Pós-Graduação em Educação em Ciências e em Matemática (PPGECM) \\ Universidade Federal do Paraná (UFPR)
}

\author{
José Claudio Del Pino (delpinojc@yahoo.com.br) \\ Programa de Pós-Graduação em Ensino (PPGENSINO) \\ Universidade do vale do Taquari (UNIVATES)
}

Resumo: Neste artigo objetiva-se, por meio das especificidades e das implicações das narrativas de sujeitos da Educação Básica, apresentar a metodologia Dicumba, bem como refletir sobre as suas potencialidades no desenvolvimento dos processos de ensino e aprendizagem e no aperfeiçoamento da prática docente à luz dos saberes intradisciplinares. A pesquisa-ação de cunho qualitativo foi desenvolvida por meio de 8 passos, enfatizando a participação de 1 professor de química e de 23 alunos do segundo ano do Ensino Médio, no ano de 2019. Para a análise dos dados, além da descrição dos achados no diário de bordo por meio da observação participante, utilizou-se a leitura e a interpretação dos trabalhos de pesquisa realizados pelos alunos, bem como a aplicação de um questionário estruturado disponibilizado eletronicamente. Ao término, foi possível averiguar que os alunos apresentam interesse em estudar química com ênfase na Dicumba, o que lhes possibilita a construção e a ressignificação de conhecimentos científicos a partir de um tema de pesquisa. Por fim, destaca-se que os sujeitos apontam que os temas de pesquisa emergem do interesse $(82,6 \%)$, da curiosidade $(69,9 \%)$ e do querer entender melhor $(52,2 \%)$, os quais se encontram, majoritariamente, relacionados à ciência $(65,2 \%)$, à saúde $(52,2 \%)$ e à sociedade $(39,1 \%)$.

Palavras-chave: Aprender pela Pesquisa Centrada no Aluno; Dicumba; Formação Docente; Processos de ensino e aprendizagem.

Abstract: This article aims, through the specificities and implications of the narratives
of Basic Education subjects, to present the Dicumba methodology, as well as to reflect
on its potentialities in the development of teaching and learning processes and in the
improvement of teaching practice in the light of intradisciplinary knowledge. The
qualitative action research was developed through 8 steps, emphasizing the participation
of 1 chemistry teacher and 23 students of the second year of high school, in 2019 . For
data analysis, in addition to the description of the findings in the logbook through
participant observation, the reading and interpretation of the research work carried out
by the students was used, as well as the application of a structured questionnaire made
available electronically. At the end, it was possible to ascertain that the students are 
interested in studying chemistry with an emphasis on Dicumba, which allows them to construct and refine scientific knowledge from a research theme. Finally, it is highlighted that the subjects point out that the research themes emerge from interest $(82.6 \%)$, curiosity $(69.9 \%)$ and wanting to understand better $(52.2 \%)$, which are found, mostly related to science $(65.2 \%)$, health $(52.2 \%)$ and society $(39.1 \%)$.

Keywords: Learning through Student-Centered Research; Dicumba; Teacher Education; Teaching and learning processes.

\section{DICUMBA: APRENDER PELA PESQUISA NO ENSINO DE QUÍMICA}

Nos últimos anos, as pesquisas relativas aos processos de ensino e aprendizagem tem aumentado significativamente, preferencialmente em relação a ciência química em detrimento a outras ciências. Diferentes metodologias, estratégias de ensino e enfoques estão sendo utilizados para qualificar o desenvolvimento do ensino de química, essencialmente em relação as questões teóricas, afinal, de acordo com Bedin (2019, p. 102), "metodologias docentes que se concentram em cálculos matemáticos e memorização de fórmulas e nomenclatura de compostos, sem a validação de fenômenos e conceitos, infelizmente, ainda hoje, são tradicionais no ensino de química”.

Neste linear, as pesquisas e as investigações atreladas ao ensino de química têm sido desenvolvidas à luz de diferentes aspectos e múltiplas tendências, enfatizando, principalmente, uma prática pedagógica contextualizada em que o sujeito é coadjuvante do processo. Este desenho no ensino de química é importante porque a contextualização pode, "além de instigar a participação do aluno para a abrangência de seus saberes e a conexão com a sua vivência, intensificar e maximizar os processos de ensino e aprendizagem de forma satisfatória na educação básica” (FINGER; BEDIN, 2019, p. 9). Ademais, as ações buscam um processo em que os conceitos e os conteúdos da ciência química são desenvolvidos a partir do contexto sociocultural do aluno, possibilitandolhe uma associação científica à própria realidade. Neste aspecto, emergem, também, discussões e estudos que relacionam as potencialidades da reconstrução curricular no ensino de química a partir do ambiente macro, vivenciado pelo aluno (GALIAZZI et al., 2004; MALDANER; ZANON, 2004; BEDIN; DEL PINO, 2019a; BEDIN, 2020).

Nesta perspectiva, levando-se em consideração que a prática didático-pedagógica no ensino de química precisa, de certa forma, potencializar a formação de um sujeito ativo, crítico e consciente em relação a sua influência na sociedade e a influência desta em sua identidade, é cogente pensar numa formação autônoma de caráter científico. De 
outra forma, a prática pedagógica em química "não deve se limitar a transmitir conteúdos e significados de símbolos e fórmulas, mas favorecer as atividades psicocognitivas dos estudantes, fazendo com que os mesmos se tornem importantes personagens na assimilação e ressignificação de conceitos” (BEDIN, 2019, p. 102).

Afinal, no contexto do ensino de química a aprendizagem do aluno deve estar para além da assimilação de conceitos ou da aquisição de informações, pautando-se no construtivismo e propiciando ao aluno a oportunidade de experimentar, analisar e interpretar situações que lhe possibilitam a formação de um espírito crítico-científico. De acordo com Bedin (2019, p. 102), tal ação é necessária "para instigar a curiosidade, o questionamento e a resolução de problemas; o construtivismo propõe que o estudante participe ativamente do próprio aprendizado, mediante a experimentação, a pesquisa em grupo, o estímulo à dúvida e o desenvolvimento do raciocínio".

Acredita-se que a prática docente construtivista, bem como a reestruturação ou a adaptação curricular, pode propiciar ao aluno a superação da passividade em relação a aquisição e a internalização de informações transpostas do livro didático, instigando-lhe a ação de (re)significar os saberes científicos emergidos em aula. Esta ação é relevante ao ensino de química porque o aluno precisa "construir e utilizar conhecimentos específicos da área para argumentar, propor soluções e enfrentar desafios locais e/ou globais, relativos às condições de vida e ao ambiente" (BRASIL, 2015, p. 470).

Contemplando as proposições e as perspectivas do documento oficial para o ensino de química (BNCC - Base Nacional Comum Curricular), percebe-se uma necessidade significativa de os elementos do conhecimento desta ciência serem desenvolvidos a partir do interesse e da curiosidade do aluno, a fim de que este possa, dentro de suas especificidades e singularidade, superar as limitações da passividade e da linearidade no ensino de química. Logo, neste texto, enfatiza-se o uso da pesquisa como princípio pedagógico à luz da metodologia Dicumba (Desenvolvimento Cognitivo Universal-Bilateral da Aprendizagem), buscando no Aprender pela Pesquisa Centrada no Aluno (APCA) as narrativas discentes sobre a emersão e a qualificação da formação docente e da aprendizagem científica.

Portanto, por meio das especificidades e das implicações das narrativas de sujeitos vinculados à Educação Básica, bem como das particularidades da ação docente no cotidiano escolar, no intuito de averiguar indícios desta ação para a formação e a 
mobilização de competências, de habilidades e de atitudes nos sujeitos, apresenta-se uma metodologia ativa denominada Dicumba, bem como se reflete sobre as suas potencialidades no desenvolvimento dos processos de ensino e aprendizagem e no aperfeiçoamento da prática docente à luz dos saberes intradisciplinares. Como pano de fundo, busca-se entender quais são as narrativas discentes utilizadas para a escolha de temas de pesquisa, assim como a influência destas na construção, na organização e na aquisição de conhecimentos químicos por meio do APCA.

Tal pesquisa se justifica na concepção de que a "Dicumba visa desenvolver autonomia, argumentação crítica e senso de expressão no aluno, permitindo-o se perceber como membro da construção de sua aprendizagem a partir da constituição de saberes científicos via interesses pessoal e social" (RANGEL; BEDIN; DEL PINO, 2019 , p. 2). Este processo é importante para motivar o aluno à aprender por meio de suas ações, estimulando a sua capacidade individual e autônoma de construir e de reconstruir argumentos críticos, científicos e coerentes com o seu contexto sociocultural, bem como caracterizar e personalizar os processos indissociáveis de ensinar e aprender.

Em síntese, a metodologia Dicumba emergiu como resultado de uma pesquisa de pós-doutorado no ano de 2018, tendo como premissa a ideia de o aluno "tornar-se, com o auxílio do professor, construtor dos próprios saberes; saberes estes que, ressignificados cientificamente ao seu contexto sociocultural, emergem a partir de sua vivência, curiosidade e interesse" (BEDIN; DEL PINO, 2019a, p. 4). Neste viés, em consonância com a teoria sócioconstrutivista, quando o professor trabalhar com a Dicumba em sala de aula ele deve considerar elementos do contexto e do interesse do aluno para desenvolver o APCA, os quais estão para além da necessidade de mediar e de desenvolver os conceitos e os conteúdos científicos curricularmente organizados. Afinal, o APCA é uma "forma prioritária de valorizar o interesse do aluno da Educação Básica e aguçar sua curiosidade por um tema, acerando sua capacidade individual e autônoma de construir e reconstruir argumentos críticos e coerentes com seu contexto sociocultural" (BEDIN; DEL PINO, 2019b, p. 1361). Não diferente, o APCA também faz com que "o professor deixa de ser o detentor do saber, o transmissor de informações prontas e acabadas, e faz com que o aluno, enquanto sujeito significativo em construção, passe a construir e a internalizar um perfil científico a partir da pesquisa realizada" (BEDIN; DEL PINO, 2020, p. 364). 
Neste sentido, entende-se que o tema de pesquisa emerge do interesse do aluno e não do professor; os conteúdos e os conceitos da ciência química são desenvolvidos a partir de um tema de pesquisa macro, o qual foi determinado pelo aluno. Este processo é importante na formação cognitiva do aluno porque as relações que ele estabelecerá com os conhecimentos científicos estarão entrelaçadas a um tema que lhe faz sentido; tratase de uma ação de ressignificar os conceitos conhecidos e solidificar conexões com o desconhecido. Bedin e Del Pino (2019a, p. 4) ajuízam que "a formação dos saberes do aluno deve partir de sua vivência e de seu interesse para que possam fazer/trazer sentido e significado", pois, assim, o docente "potencializará a aprendizagem do aluno através da pesquisa centrada em seu contexto, possibilitando a este a revisão de saberes para a (re)construção de seus conhecimentos".

Assim, o aprendizado do aluno é favorecido na medida em que ele, colaborativamente com o professor, estabelece relações significativas entre aquilo que ele conhece (tema de pesquisa) com os saberes que ele desconhece (conhecimento científico). Este processo que propicia ao aluno e ao professor uma intensa interação com o conhecimento, quando desenvolvida de forma ativa e comprometida, leva a aprendizagem satisfatória. Logo, é possível mensurar que a Dicumba, via APCA, pode trazer a tona por meio da pesquisa do aluno um número significativo de conceitos da ciência química, proporcionando ao professor a introdução do conteúdo cientifico por diferentes vieses, o qual pode evoluir com a participação ativa do aluno. Ademais, o professor pode estimular a criatividade do aluno, individual ou coletiva, solicitando-lhe a entrega da pesquisa científica por algo diferente do teórico, bem como potencializar a aprendizagem deste a partir da significação de conceitos advindos de seu interesse.

De acordo com o supracitado, entende-se que a reestruturação ou a adaptação do currículo é necessária quando se trabalha com a Dicumba, pois o ensino parte de uma situação vivencial do aluno e não de uma sequência linear estruturada curricularmente. Assim, Bedin e Del Pino (2018b, p. 345-346) afirmam que a Dicumba exige "uma extrusão no currículo escolar, instigando o professor a pensar em novas maneiras de selecionar e organizar os conteúdos a partir da realidade sociocultural do aluno, contemplando a formação deste a partir do contexto em que está inserido". Ademais, os autores afirmam que o currículo no ensino de química na Educação Básica "encontra-se fragmentado e defasado na maioria das escolas públicas do estado gaúcho, pois, em sala 
de aula, constrói-se conhecimentos que já se encontram nos livros didáticos, sem conexão e/ou vínculo com a vivência do aluno” (BEDIN; DEL PINO, 2019b, p. 349).

$\mathrm{Na}$ prática, a Dicumba, apesar de não ter um receituário ou uma direção específica, sólida e imaleável, pode ser desenvolvida seguindo as etapas presentes no SmartArt 1, de acordo com Bedin e Del Pino (2018a). Ressalva-se que tais etapas não se restringem especificamente ao trabalho docente, mas são necessárias para que o aluno compreenda seu papel dentro do APCA.

$O$ professor solicita ao aluno que pense em um tema de pesquisa que lhe desperta o interesse e a curiosidade, realizando uma pesquisa universal sobre ele.

O aluno socializa a sua pesquisa em sala de aula, enquanto que o professor, com enfase na pesquisa, elabora questionamentos científicos à luz da ciência química.

O professor solicita ao aluno que realize uma nova pesquisa com base em seus questionamentos, agora de caráter científico, apresentando-a em sala de aula.

Ao socializar a pesquisa em sala de aula, o aluno apresenta conceitos da ciencia química que são a base para o professor introduzir e desenvolver os conteúdos.

Figura 1: Protótipo de Etapas para o Desenvolvimento da Dicumba Fonte: os autores, 2020.

Neste sentido, tendo como base o apresentando no SmartArt 1, percebe-se que a Dicumba é mais uma metodologia de ensino que busca a qualificação dos processos de ensino e aprendizagem centradas no aluno como pessoa, buscando valorizar, como destacam Bedin e Del Pino (2019b, p. 1360),

1 - a união entre o dizer e o fazer docente (o professor passa a ser facilitador do processo de ensinagem); 2 - a conexão entre a prática de pesquisar e ensinar (o aluno aprende e ensina na medida em que pesquisa); 3 - a vinculação entre formação e profissionalização (o professor, mesmo diante de um sistema educacional maçante, coloca em prática seus aprendizados filosóficos, pedagógicos e epistemológicos da graduação) e 4 - a valorização do saber do aluno para o desenvolvimento de competências e habilidades relacionadas ao saber científico.

No APCA a abordagem dos conteúdos em sala de aula ocorre a partir dos conceitos que os alunos trazem de suas pesquisas, propiciando a valorização da ação destes e a mobilização de competências e atitudes enquanto sujeitos ativos e pensantes. 
Reconhecer o papel do aluno, bem como o de seus conhecimentos sociais dentro dos processos de ensino e aprendizagem da ciência química, é uma forma de possibilitar a contextualização do objeto de estudo, "o que faz com que os conceitos cotidianos se façam presentes e passem a interagir com os conceitos científicos que são introduzidos" (MALDANER et al., 2001, p. 6).

Portanto, destaca-se, dentre os benefícios da metodologia Dicumba presentes no SmartArt 2, oriundos de Rangel, Bedin e Del Pino (2019, p. 7), o constante movimento da significação conceitual, a qual decorre de uma ação conjunta entre o professor e o aluno.

\section{A aprendizagem deriva do interesse e da curiosidade do aluno}

O aluno pesquisa para (re)construir e (re)significar saberes à laz do cientííco

Os conteńdos cientíícos de química sāo desenvolvidos a partir de um tema de escollha do aluno

A química é interpretada no mudo macro e, entāo, estudada no mundo micro

\section{O professor passa a ser potencializador da aprendizagem}

\section{A metodologia requer atualizaçāo e aperfeiçoamento docente}

Figura 2: Benefícios decorrentes da utilização da Dicumba em sala de aula. Fonte: Rangel, Bedin e Del Pino (2019, p. 7).

Diante do exposto, e considerando os achados na literatura que fazem menções a influência da abordagem socioconstrutivista na formação do sujeito por meio de ações como o Educar pela Pesquisa e a Abordagem Temática, percebe-se que a Dicumba está mais associada aos processos de ensino e aprendizagem, os quais derivam do interesse e do desejo do aluno, do que a formação docente e a seleção de temas. Nesta perceptiva, apesar de a Dicumba estar associada a diferentes estudiosos, como Freire (2005), Vygotsky (1989) e Piaget (1998), a metodologia se concentra especificamente nas concepções de Rogers (2001), diferenciando-se das demais. Além disso, a metodologia pressupõe o desenvolvimento dos objetos de conhecimento da ciência química a partir dos achados nas pesquisas dos alunos, banalizando as ações docentes a partir destes. 
Tal perspectiva é essencial no processo da Dicumba, pois o APCA em sala de aula depende de um movimento prazeroso e potencializador para ser desenvolvido de forma eficiente e centrado no aluno como pessoa; movimento este em que o professor assume uma postura humanista frente as suas ações, uma vez que "a didática centrada na pessoa enfatiza o professor e o aluno como pessoas e sua relação existe em um clima de respeito mútuo, onde cabe ao professor, basicamente, dar ao aluno condições favoráveis para desenvolver seu potencial intelectual e afetivo" (ROGERS, 2001, p. 52). Portanto, para sintetizar as ideias, o SmartArt 1 apresenta as concepções teóricas da Dicumba, relacionando a ação do aluno com o seu contexto, perpassando pela descoberta por meio da pesquisa e centrando-se no amadurecimento cognitivo a partir da interiorização dos signos, para solidificar a sua identidade como pessoa e não simplesmente como aluno.

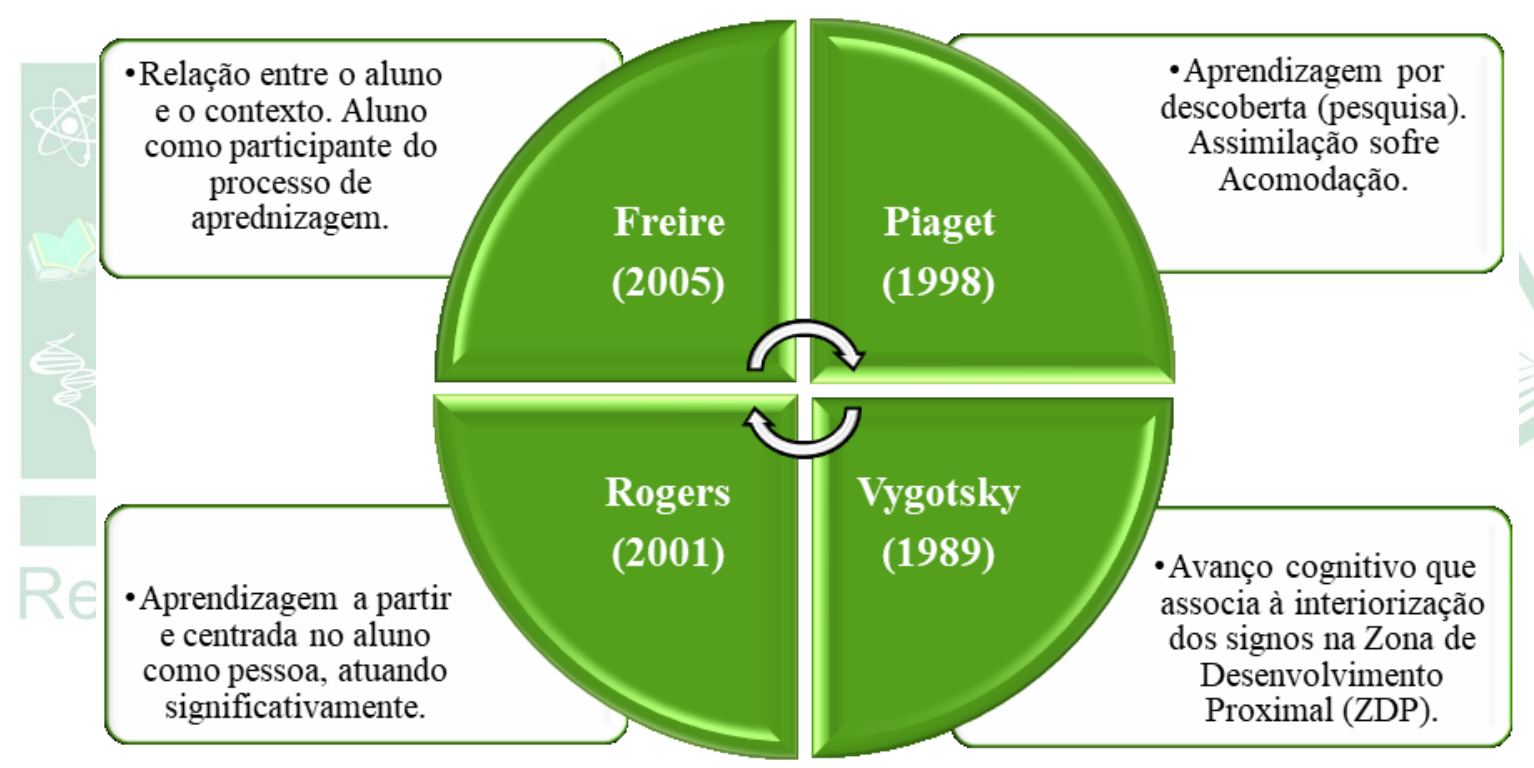

SmartArt 1: Teorias que banalizam a metodologia Dicumba.

Fonte: os autores, 2020.

\section{METODOLOGIA DA PESQUISA}

Esta pesquisa de cunho qualitativo foi desenvolvida durante três meses à luz da pesquisa-ação com a participação ativa de 1 professor de química (pesquisador) e de 23 alunos da segunda série do Ensino Médio de uma escola pública situada em São Leopoldo, região metropolitana de Porto Alegre, capital do Estado do Rio Grande do Sul. A pesquisa foi considerada em um viés de pesquisa-ação porque esta é uma forma de pesquisa em que o pesquisador também "é uma pessoa da prática e se deseja melhorar a compreensão desta" (ENGEL, 2000, p. 182). Isto é, considerando que o 
professor atuou significativamente no processo do desenvolvimento da Dicumba, buscando aperfeiçoar-se didático e pedagogicamente, é cogente destacar que a pesquisa tornou-se "um processo de aprendizagem para todos os participantes e a separação entre sujeito e objeto de pesquisa deve ser superada" (KRAPP, 1982, p. 61).

Ademais, este processo é importante porque por meio da pesquisa-ação, segundo Tripp (2005, p. 445), o docente pode "utilizar suas pesquisas para aprimorar seu ensino e, em decorrência, o aprendizado de seus alunos". Neste processo "planeja-se, implementa-se, descreve-se e avalia-se uma mudança para a melhora de sua prática, aprendendo mais, no correr do processo, tanto a respeito da prática quanto da própria investigação" (TRIPP, 2005, p. 446). Neste linear, o professor utilizou um diário de bordo para conseguir detalhar todas as atividades desenvolvidas, bem como fragmentos de diálogos entre os alunos e entre ele e os alunos. O diário de bordo foi essencial neste processo, pois é considerado "um registro de experiências pessoais e observações passadas, em que o sujeito que escreve inclui interpretações, opiniões, sentimentos e pensamentos, sob uma forma espontânea de escrita, com a intenção usual de falar de si mesmo" (ALVES, 2001. p. 224), tornando-se possível "identificar as dificuldades encontradas, os procedimentos utilizados, os sentimentos envolvidos, as situações coincidentes, as situações inéditas" (SANTOS, 2005, p. 70).

Neste sentido, para a coleta de dados, além da observação participante, o professor utilizou o diário de bordo, a aplicação de um questionário virtual e as pesquisas desenvolvidas pelos alunos e entregues em forma de cards. Logo, para a análise dos dados, além da descrição dos achados no diário de bordo por meio da observação participante, utilizou-se a leitura e a interpretação dos trabalhos de pesquisa realizados pelos alunos, bem como as concepções e os pressupostos dos colaboradores desta pesquisa presentes no questionário estruturado disponibilizado por meio virtual. Em síntese, entende-se que o questionário, nesta pesquisa, foi aplicado eletronicamente via plataforma Google Forms, onde se gerou um link para o acesso, o qual foi enviado aos participantes via WhatsApp, sendo que ao responderem o questionário, o registro dos dados era efetuado automaticamente na própria plataforma.

Posteriormente, os dados foram analisados detalhadamente, considerando as colocações dos sujeitos, bem como a interpretação empírica e transversal das pesquisas desenvolvidas pelos alunos à luz da Dicumba, as quais foram cruzadas por meio do programa Statistical Package for the Social Sciences (SPSS) e discutidas com base nos 
teóricos da área. Assim, para a análise via SPSS em relação ao perfil dos alunos, fez-se um cruzamento dos dados relacionados a categoria Gênero com os dados relacionados a categoria Faixa Etária, considerando esse padrão como meio de demonstração.

\section{RESULTADOS E DISCUSSÃO}

Considerando que neste texto buscou-se essencialmente apresentar uma metodologia ativa denominada Dicumba, bem como refletir sobre as suas potencialidades no desenvolvimento dos processos de ensino e aprendizagem e no aperfeiçoamento da prática docente à luz dos saberes intradisciplinares, julgou-se importante descrever detalhadamente como ocorreu o desenvolvimento da atividade. Afinal, este processo é importante para entender as especificidades e as implicações das narrativas dos sujeitos desta pesquisa vinculados à Educação Básica, bem como das particularidades da ação docente, possibilitando averiguar indícios desta ação para a formação e a mobilização das competências, das habilidades e das atitudes nos sujeitos.

Neste viés, a Tabela 1 apresenta as ações desenvolvidas pelo professor e pelos alunos em relação a atividade de pesquisa em sala de aula, enfatizando o objetivo de cada uma destas ações.

Tabela 1: Ações e objetivos utilizados para o desenvolvimento da Dicumba.

\begin{tabular}{l|l}
\multicolumn{2}{c}{ Ações } \\
\hline $\begin{array}{l}\text { Instigar o pensamento } \\
\text { sociocultural. }\end{array}$
\end{tabular}



futuros desdobramentos.

Introduzir os conteúdos científicos.

Fonte: os autores, 2020.

Introduzir e desenvolver os conteúdos da ciência química a partir dos conceitos apresentados pelos alunos durante a apresentação de suas pesquisas científicas.

Com base nas ações presentes na Tabela 1, compreende-se que a atividade desenvolvida por meio da Dicumba em um espaço-tempo de três meses foi otimizada de forma colaborativa entre o professor e os alunos. Ademais, pode-se perceber que cada aluno desenvolveu a sua pesquisa de forma individual, uma vez que o tema para a emersão e o desenvolvimento da mesma emergiu da realidade sociocultural do aluno; logo, cada aluno pensou em seu contexto e elencou um tema social para desenvolver a sua pesquisa universal. Este processo respalda-se na ideia de que a pesquisa propõe a problematização inicial sobre o conhecimento que o aluno detém, a fim de que o diálogo seja desenvolvido de formas reconstrutiva e questionadora, construindo e reconstruindo argumentos que, além de promoverem a comunicação entre os pares, enfatizando a fala e a escrita, valorizem a função epistêmica deste processo (MORAES; GALIAZZI, RAMOS, 2004; BEDIN, 2020).

Como supracitado, a Dicumba foi desenvolvida em uma turma contendo 23 alunos, dos quais, conforme Quadro 1, 43,5\% $(\mathrm{n}=10)$ são do gênero masculino e $56,5 \%(n=13)$ são do gênero feminino. Ainda, com base no quadro, pode-se perceber que a faixa etária destes varia entre 16 anos $(21,7 \%, \mathrm{n}=5)$ e 18 anos $(13,0 \%, \mathrm{n}=3)$, sendo a sua maioria com 17 anos $(65,2 \%, \mathrm{n}=15)$.

Quadro 1: Gênero e Faixa Etária dos alunos participantes da pesquisa.

\begin{tabular}{|c|c|c|c|}
\hline \multirow{4}{*}{ نِّ } & & Frequência & Porcentagem \\
\hline & Masculino & 10 & 43,5 \\
\hline & Feminino & 13 & 56,5 \\
\hline & Total & 23 & 100 \\
\hline \multirow{5}{*}{ 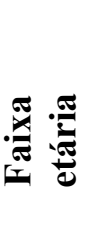 } & & Frequência & Porcentagem \\
\hline & 16 & 5 & 21,7 \\
\hline & 17 & 15 & 65,2 \\
\hline & 18 & 3 & 13,0 \\
\hline & Total & 23 & 100 \\
\hline
\end{tabular}

Fonte: dados da pesquisa tabulados por meio do SPSS.

Em relação as questões disponibilizadas no questionário online, solicitou-se ao aluno para que justificasse a escolha do tema, bem como que apontasse a área de 
pesquisa e os possíveis motivos da escolha pelo tema. Tais questionamentos servem para entender quais são os motivos e os assuntos que despertam o interesse do aluno em pesquisar e, a partir desta ação, estudar para aprender. Neste sentido, entende-se que a Dicumba é uma metodologia ativa capaz de instigar e de estimular o aluno a aprender química por meio da pesquisa como um princípio pedagógico, bem como favorecer a sua formação sociocultural a partir de um tema de interesse e de curiosidade, o qual se relaciona significativamente aos conteúdos científicos da ciência química a partir das ações didático-pedagógicas de forma intradisciplinar.

Neste linear, Demo (1997) afirma que a importância da pesquisa para a educação encontra-se na fundamentação do interesse do aluno, enfatizando a pesquisa como uma forma própria de aprendizagem, onde o aluno deixe de ser o objeto do ensino e passa a ser o parceiro de trabalho. Neste sentido, Kierepka e Zanon (2019, p. 18) expõem que a problematização sobre a prática na pesquisa é uma forma de possibilitar ao professor o repensar de seus pressupostos epistemológicos em relação a ação pedagógica, o que possibilita "o reconhecimento e enfrentamento de problemas da própria prática docente, que é um processo necessário para a transformação das ações docentes e que incidem também em revisões nas teorias que guiam a prática”. Isto é, a pesquisa em sala de aula é uma forma de potencializar a formação dos sujeitos, instigando-os ao aperfeiçoamento colaborativo, conjunto e dialógico.

Quando questionados em relação a escolha do tema, os alunos refletem que escolhem-no porque gostam do assunto, sentem curiosidade em falar sobre, bem como buscam aprofundamento teórico e epistemológico. Ademais, os alunos justificam a escolha porque acreditam que o tema está relacionado a futura profissão ou porque convivem diariamente com isso, já que é parte integral de seus afazeres ou, em casos específicos, presentes na família, como apresenta os excertos abaixo (Quadro 2). Ressalva-se que os excertos são expostos como apresentados no questionário; logo, optou-se em expô-los na forma com a qual os alunos escreveram/justificaram, sem fazer alterações ou adequações linguísticas.

Quadro 2: Excertos das ponderações dos alunos sobre a justificativa pela escolha do tema.

Eu escolhi esse tema porque eu gosto de bomba, arma, essas coisas, e eu queria saber o que é, e como funciona uma bomba de hidrogênio (A1).

Tenho uma agência de marketing digital e sei o quanto é necessário para empresas e micro empresas (A3).

Porque é um assunto que eu gosto e tenho mais facilidade de falar, além de que é a minha 
profissão futura, e com trabalhos como esse, vou adquirir novos conhecimentos dessa área que futuramente vai me ajudar muito (A4).

Porque eu gosto de falar sobre o meio ambiente, do que ta acontecendo com ele (A5).

Por que eu faço academia e sou facinado por isso (A7).

É um assuntos que engloba minhas curiosidades, crenças e a religião em sí (A8).

Sempre tive uma curiosidade por mutações genéticas, como elas atingem o corpo e como se propagam. Já li muito sobre o assunto e o local onde mais se abordava esse tipo de tema era nos circo dos horrores e em laboratórios (A9).

Pois vi em outra matéria escolar, e fiquei curioso para saber mais (A10).

Música está no cotidiano, e é algo que eu tenho uma grande paixão (A11).

Escolhi esse tema, pois é um assunto bem relevante que retrata uma realidade que estamos vivenciando na nossa atualidade (A14).

Escolhi este tema porque tenho pessoas na minha familia com epilepsia e me interessou (A16).

Fonte: dados da pesquisa, 2019. (grifo nosso)

Considerando os excertos no Quadro 2, percebe-se que os alunos escolhem assuntos que estão diretamente relacionados aos próprios interesses, sejam eles familiares, profissionais, sociais ou culturais. Neste contexto, entende-se que se o professor não tivesse possibilitado aos sujeitos o APCA, talvez, eles não teriam compreendido a ciência química presente em seu cotidiano e, quiçá, estudado algo relativamente fundamentado em sua importância, na disciplina de química. Assim, percebe-se a significância de o professor conseguir relacionar todos os temas elencados em sala de aula para a ação de pesquisar com os conceitos da ciência química, demonstrando a universalidade e a bilateralidade da Dicumba, bem como exercendo a democracia e a essência do APCA.

Não diferente, Bedin e Del Pino (2018b) salientam a necessidade de o professor valorizar os temas de pesquisa dos sujeitos, independente do cronograma ou da estrutura curricular imposta na Educação Básica, pois os autores acreditam que, indiferente do conceito ou do assunto a ser aprendido a partir do APCA, os alunos terão contato satisfatório com o conteúdo científico da ciência. Portanto, com ênfase na Dicumba, entende-se que é preciso "superar a lógica disciplinar e a superposição de conteúdos gerais e específicos, para que sejam empregadas novas formas de seleção e organização dos conhecimentos" (BEDIN, 2015, p. 34), bem como possibilitar ao aluno aprender a partir daquilo que lhe motiva e lhe desperta interesse. Afinal, Constantino et al., (2019, p. 248) afirmam que "os sujeitos envolvidos no processo de aprendizagem ao questionar 
e problematizar sua realidade se apropriam de maneira significativa dos conceitos estudados", o que lhes propicia a aprendizagem.

Posteriormente a justificativa pelo tema de pesquisa, os alunos foram convidados, a partir de uma questão fechada, a qual apresentava alguns possíveis ensejos, a apontar os motivos que os levaram a optar pelo tema, conforme Gráfico 1. Ressalva-se que no gráfico é possível identificar os motivos disponibilizados no questionário, bem como os percentuais de escolha pelos alunos. Ademais, aponta-se que os alunos podiam escolher mais de um motivo, o que faz com que o somatório no percentual seja superior a $100 \%$.

Gráfico 1: Apontamento em percentual dos sujeitos sobre os motivos de escolha pelo tema.

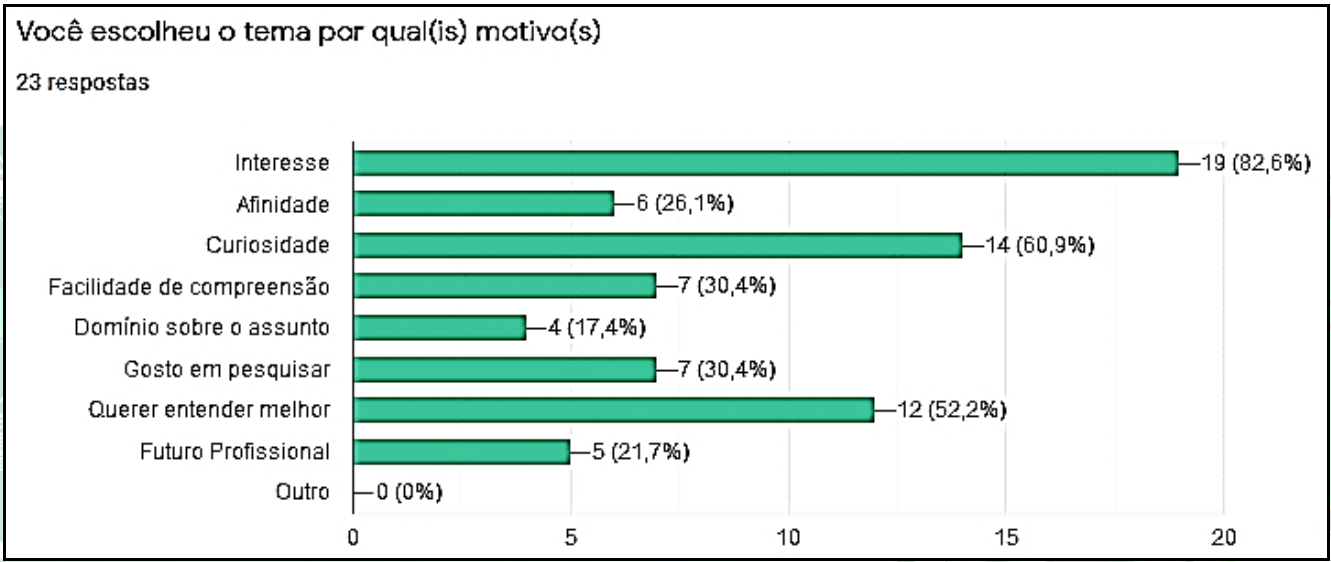

Fonte: dados da pesquisa via SPSS, 2019.

A partir do Gráfico 1, para entender as colocações dos sujeitos à luz da análise estatística via SPSS, considerando o cruzamento de dados em relação a categoria gênero, plotou-se o Gráfico 1.1. Neste viés, percebe-se no Gráfico 1 que nenhum dos alunos apontou o termo "outro" como motivo pela escolha do tema, denotando todas as demais possibilidades disponibilizadas pelo professor. Além disso, percebe-se que a escolha por estes temas variou bastante, mas a grande maioria aponta o motivo Interesse $(82,6 \%, \mathrm{n}=19)$, seguido de Curiosidade $(60,9 \%, \mathrm{n}=14)$ e Querer Entender Melhor $(52,2 \%, \mathrm{n}=12)$.

Gráfico 1.1. Percentual dos sujeitos em relação ao gênero sobre os motivos de escolha pelo tema. 


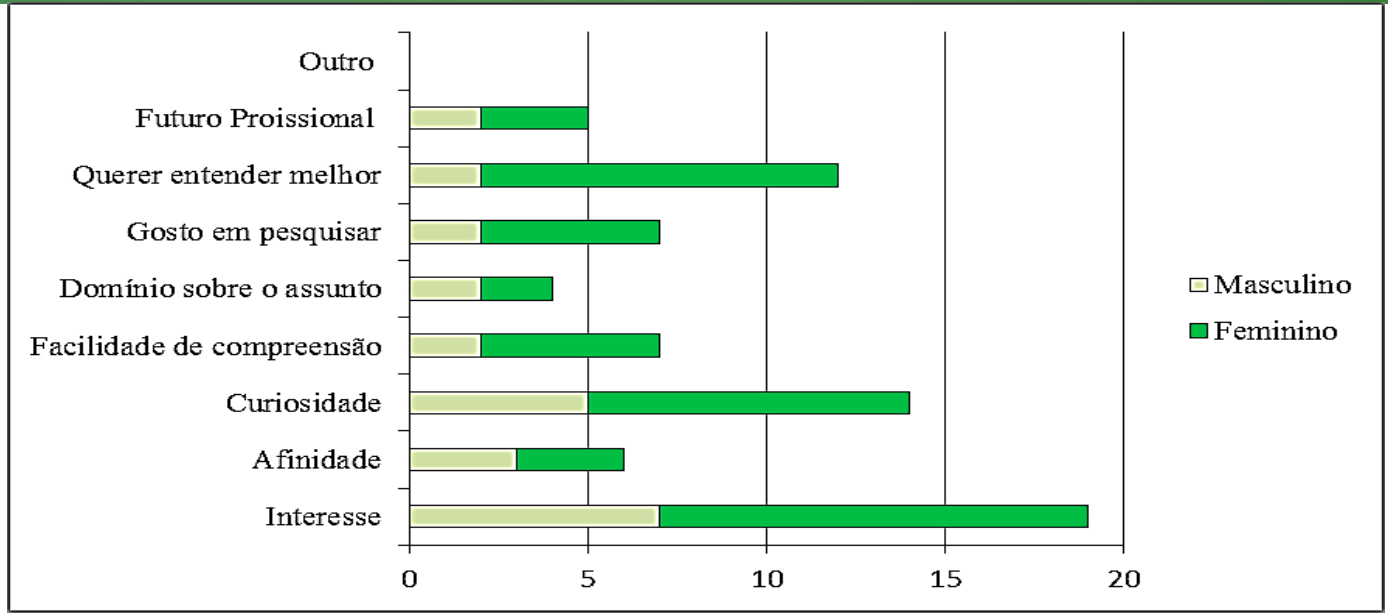

Fonte: dados da pesquisa via SPSS, 2019.

Em relação ao Gráfico 1.1, pode-se afirmar que dos 19 alunos que optam pelo motivo Interesse, 7 alunos são do gênero masculino e 12 alunos são do gênero feminino, enquanto que em relação ao motivo Curiosidade 5 alunos são do gênero masculino e 9 são do gênero feminino; em relação ao motivo Querer Entender Melhor, tem-se que 2 alunos são do gênero masculino e 10 alunos são do gênero feminino. Apesar de não haver, e aqui não se fazer, distinção entre os gêneros, ao retomar a ideia de que a turma é composta por 10 alunos do gênero masculino e 13 alunos do gênero feminino, pode-se perceber que mais de $50 \%$ dos alunos do gênero feminino apontam pelos três motivos com majoritariedade, enquanto que apenas um dos motivos (Interesse) é apontado por mais de 50\% dos alunos do gênero masculino.

Neste aporte, indiferente do gênero, percebe-se que o grande motivo da escolha pelo tema que será pesquisado pelo aluno, e relacionado aos conteúdos científicos da ciência química pelo professor, deriva do interesse do aluno. Este desenho é importante porque quando o aluno percebe que ele é quem está determinando o tema que será estudado, possivelmente, desenvolve criticidade, autonomia e identidade de participação ativa em sala de aula; é assim, de acordo com Bedin e Del Pino (2018a), que tem êxito a Dicumba. A participação no processo de aprendizagem fez com que os sujeitos conseguissem desenvolver "competências relacionadas a argumentação crítica, autonomia de escolhas e, principalmente, capacidade da ação-reflexão-ação" (BEDIN; DEL PINO, 2018a, p. 73). Afinal, "por meio da conjugação do esforço intelectual com o compromisso problematizador da pesquisa, foram trabalhados saberes sociais, culturais e científicos" (BEDIN; DEL PINO, 2018a, p. 73), os quais derivaram, restritamente, das concepções dos alunos. 
Ademais, o questionamento, a argumentação e a comunicação, elementos que fundamentam a pesquisa em sala de aula na visão de Moraes, Galiazzi e Ramos (2004), emergiram e foram essenciais para e no processo. Neste aporte, compreende-se que é necessário haver protagonismo dos alunos e do professor no processo do APCA; logo, deve-se pensar num ambiente de sala de aula onde os sujeitos possam interagir significativamente, em que "o professor constitui-se mediador e o aluno assume a responsabilidade de participar na construção de seus conhecimentos, de forma a exercer a sua autonomia" (KIEREPKA; ZANON, 2019, p. 13), validando o papel democrático, colaborativo e dinâmico do APCA.

Em relação a área de interesse de pesquisa dos alunos, sugeriu-se aos sujeitos que apontassem, dentro de uma questão fechada, as possíveis áreas disponibilizadas pelo professor, conforme Gráfico 2. Ressalva-se que, assim como na questão relacionada aos motivos de escolha, os alunos podiam escolher mais de uma área; logo, o somatório no percentual também fica superior a $100 \%$.

Gráfico 2: Apontamento em percentual dos sujeitos em relação a área de pesquisa.

O teu tema se encaixa em qual(is) dessas áreas:

23 respostas

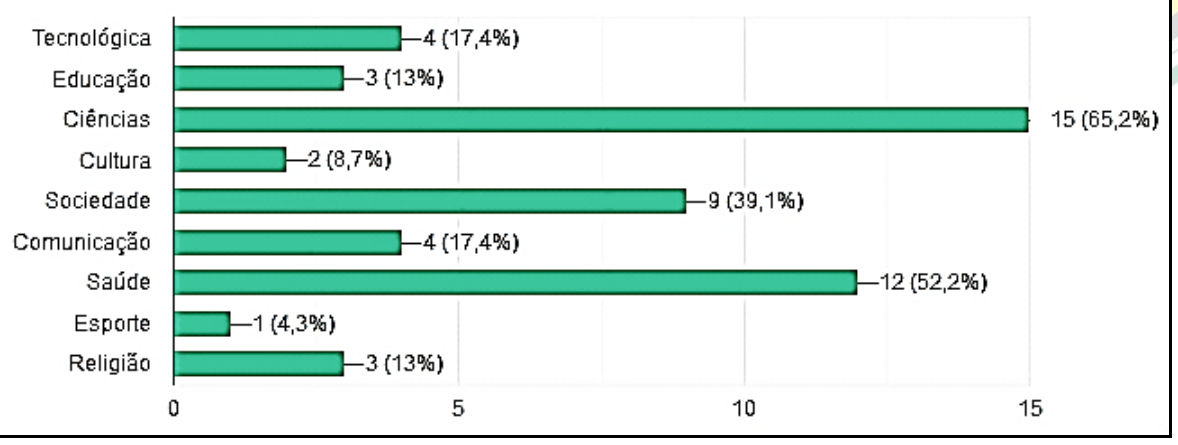

Fonte: dados da pesquisa via SPSS, 2019.

Em relação ao gráfico acima, percebe-se que a grande maioria dos alunos aponta como áreas vinculadas as suas pesquisas, em ordem decrescente, Ciências, Saúde, Sociedade, Comunicação, Tecnológica, Educação, Religião e Cultura. Todavia, as áreas com maior aderência, na perspectiva dos sujeitos, são: Ciência $(65,2 \%, \mathrm{n}=15)$, Saúde $(52,2 \%, \mathrm{n}=12)$ e Sociedade $(39,1 \%, \mathrm{n}=9)$. Neste sentido, como realizado para a questão anterior, com base no software SPSS, cruzou-se os dados por meio da categoria gênero, plotando-se o Gráfico 2.1. 
Gráfico 2.1. Percentual dos alunos em relação ao gênero sobre às áreas relacionadas ao tema de pesquisa.

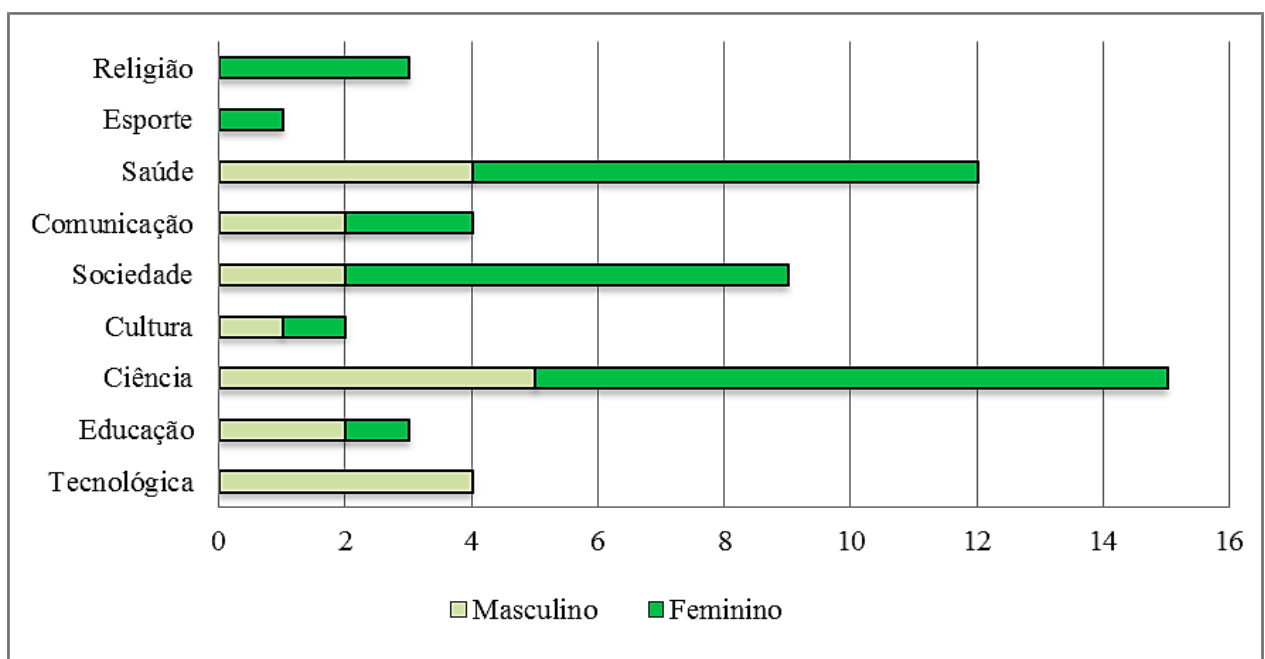

Fonte: dados da pesquisa via SPSS, 2019.

Considerando o Gráfico 2.1, bem como as áreas de maior aderência as pesquisas dos alunos na percepção destes, é possível afirmar que dos $65,2 \%$ dos sujeitos que apontam a Ciência como área majoritária, 43,47\% $(\mathrm{n}=10)$ são alunos do gênero feminino e $21,73 \%(\mathrm{n}=5)$ são alunos do gênero masculino. Nesta linha, dos 52,2\% dos alunos que apontam a área da Saúde como segundo maior vínculo as pesquisas, $34,81 \%$ $(\mathrm{n}=8)$ são alunos do gênero feminino e $17,39 \%(\mathrm{n}=4)$ são alunos do gênero masculino. Não diferente, na área Sociedade o percentual feminino ficou maior $(30,43 \%, n=7)$ em relação ao percentual do gênero masculino $(8,69 \%, n=1)$, de um total de $39,1 \%$.

Neste sentido, apesar de não se fazer distinção de gênero, por meio desta pesquisa, e exclusivamente nesta turma (público alvo), pode-se perceber que mais da metade do grupo caracterizado pelo gênero feminino aponta as três grandes áreas (Ciência, Saúde, Sociedade) como conglutinantes as suas pesquisas. Todavia, apenas uma área (Ciência) é apontada pela metade do número de alunos que contempla o gênero masculino. Nesta linha, é possível perceber algumas questões interessantes no Gráfico 2.1, dentre elas: se a pesquisa emerge do contexto do aluno, do seu interesse e de sua curiosidade, porque a área Cultura não é apontada por 91,3\% dos sujeitos?; e, - se considerarmos a ideia historicamente construída de que o gênero feminino tem aderência à área da Educação e o gênero masculino proximidade à área de Esportes, porque no Gráfico 2.1 o percentual do gênero masculino é maior na área Educação e a área Esportes é apontada apenas pelo gênero feminino? 
Diante do exposto, indiferente dos questionamentos, percebe-se que a pesquisa como veículo pedagógico de formação e de constituição de identidade deveria, numa perspectiva socioconstrutivista e centrada no aluno como pessoa, estar presente na Educação Básica em todas as áreas do saber, a fim de proporcionar ao aluno múltiplas ações, dentre elas: trocar informações, construir saberes e sistematizar conhecimentos embasados em temas que, realmente, são relevantes e importantes para ele. Isto é, por meio da Dicumba, sem distinções de gênero ou restrições de temas, o aluno é capaz de aprender química por meio daquilo que lhe desperta o interesse e lhe motiva a querer aprender mais, buscando a excelência de sua formação como pessoa; como cidadão. Assim, Demo (1997) e Bedin (2020) ajuízam que o aluno e o professor devem manejar a pesquisa como uma estratégia de princípios científico e educativo, tendo-a como atitude cotidiana. Portanto, a partir das contribuições de Bedin e Del Pino, Moraes, Galiazzi e Ramos e Demo, acredita-se que a pesquisa necessariamente deve ser considerada uma prática diária nas escolas, potencializando o ensino e intensificando a aprendizagem, para efetivar a participação coletiva, integrativa e cooperativa entre os sujeitos.

Em comunhão, é necessário perceber que a pesquisa no ensino de química pode favorecer a aprendizagem do aluno em múltiplos vieses, inclusive no sentido deste preparar-se cognitivamente para agir e interagir na e em sociedade, uma vez que a ação do APCA promove "espaços de questionamentos, argumentos e comunicação em sala de aula" (CONSTANTINO et al., 2019, p. 253). Portanto, torna-se coerente pensar e refletir sobre a possibilidade de a Dicumba estar vinculada as ações docentes na Educação Básica não como uma personificação de resultados positivos para o ensino, "mas como um mecanismo de qualificação de práticas, conjugando sua realização empírica enquanto estrutura de respaldo aos interesses e atividades do aluno e na formação docente como parte integrante desta" (BEDIN; DEL PINO, 2019b, p. 1360). Assim, ressalva-se que "quanto maior o contato com a pesquisa na sala de aula, maior será a capacidade de crítica, criação, discussão, escrita, argumentação, debate, questionamento e comunicação desenvolvida junto com o aluno" (FRESCHI; RAMOS, 2009, p. 159).

\section{CONCLUSÃO}


Considerando as potencialidades da pesquisa como um princípio pedagógico, a qual transpassa os descompassos do cotidiano escolar e a formação de professores para o ensino de química na Educação Básica, neste artigo apresentou-se as narrativas e os apontamentos de sujeitos vinculados à Educação Básica sobre uma atividade desenvolvida à luz da metodologia Dicumba, enfatizando o APCA. Ademais, buscou-se refletir sobre as potencialidades desta metodologia no desenvolvimento dos processos de ensino e aprendizagem e no aperfeiçoamento da prática docente à luz dos saberes intradisciplinares com ênfase no interesse e na curiosidade do aluno.

Neste sentido, com base no apresentado no texto, é possível afirmar que os alunos, preferencialmente, apontam a positividade em relação a Dicumba por poderem ter a opção de escolher de forma autônoma e universal o tema de pesquisa que será trabalhado pelo professor em um viés científico. Isto é importante porque os temas de pesquisa emergem da realidade dos sujeitos, principalmente com ênfase em assuntos relacionados a profissão, a família, ao interesse, ao contexto e a curiosidade. Estes temas estão entrelaçados no convívio diário dos alunos, o que lhes possibilita, numa ressignificação científica, construir conhecimentos mais sólidos e significativos.

Ademais, em relação aos motivos pela escolha, tanto quando a área de aderência, pode-se perceber, por meio dos gráficos 1 e 2, que os sujeitos preferem estudar química a partir do APCA à luz de temas que emergem do interesse $(82,6 \%)$, da curiosidade $(69,9 \%)$ e do querer entender melhor $(52,2 \%)$, os quais se encontram, majoritariamente, relacionados às áreas da ciência $(65,2 \%)$, da saúde $(52,2 \%)$ e da sociedade $(39,1 \%)$. Em especial, destaca-se o grupo composto pelo gênero feminino, pois este contempla com notoriedade as três áreas supracitadas. Todavia, como já destacado, estes dados são exclusivos deste universo de alunos, o que significa que o desenvolvimento da Dicumba, estreitamente idêntico ao desenvolvido pelo professor presente na tabela 1 , bem como a aplicação do mesmo questionário, pode resultar em dados totalmente diferentes.

Em suma, a Dicumba abrange questões da visão construtivista, tanto na dimensão teórica (epistemológica) quanto na dimensão prática (pedagógica). Em decorrência destes fatos, a proposta da Dicumba atrelada ao APCA busca um ensino contextualizado, dinâmico e intradisciplinar, no qual os conceitos e os conteúdos da ciência química são desenvolvidos a partir do interesse e da singularidade dos alunos, enfatizando uma abordagem didático-pedagógica que, além de incluir múltiplos níveis 
de abstração, fundamenta-se em diversas fontes de informações. Assim, sugere que a

Dicumba seja desenvolvida em outros vieses e contextos, principalmente naqueles em que há sujeitos desinteressados e desmotivados, a fim de validar o papel desta metodologia, também, como um mecanismo de superação e valorização discente.

\section{REFERÊNCIAS}

ALVES, Francisco Cordeiro. Diário-um contributo para o desenvolvimento profissional dos professores e estudo dos seus dilemas. Millenium, p. 222-239, 2004. Disponível em: https://repositorio.ipv.pt/handle/10400.19/578. Acesso em: 18 jul. 2020.

BEDIN, Everton. Do algodão doce à bomba atômica: avaliações e aspirações do aprender pela pesquisa no ensino de Química. Debates em Educação, v. 12, n. 27, p. 236-253, 2020. Disponível em: https://www.seer.ufal.br/index.php/debateseducacao/article/view/9587. Acessado em: 13 jun. 2020.

BEDIN, Everton. Filme, experiência e tecnologia no ensino de ciências química: uma sequência didática. Revista de Educação, Ciências e Matemática, v. 9, n. 1, 2019. Disponível em: http://publicacoes.unigranrio.edu.br/index.php/recm/article/view/4280. Acessado em: 17 jul. 2020.

BEDIN, Everton; DEL PINO, José Claudio. La movilización de competencias y el desarrollo cognitivo universal-bilateral del aprendizaje en la enseñanza de las ciências. Revista Paradigma. Edición Cuadragésimo Aniversario: 1980-2020, n. XLI, p. 360383, 2020. Disponível em: https://doi.org/10.37618/PARADIGMA.1011-2251.0.p360383.id804. Acessado em: 11 jun. 2020.

BEDIN, Everton; DEL PINO, José Claudio. DICUMBA: uma proposta metodológica de ensino a partir da pesquisa em sala de aula. Ensaio Pesquisa em Educação em Ciências, v. 21, 2019a. Disponível em: http://www.scielo.br/pdf/epec/v21/1983-2117epec-21-e10456.pdf. Acesso em: 20 jul. 2020.

BEDIN, Everton; DEL PINO, José Claudio. Das Incertezas às Certezas da Pesquisa não Arbitrária em Sala De Aula Via Metodologia Dicumba. Currículo sem Fronteiras, v. 19, n. 3, p. 1358-1378, 2019b. Disponível em: http://dx.doi.org/10.35786/16451384.v19.n3.32. Acesso em: 25 jul. 2020.

BEDIN, Everton; DEL PINO, José Claudio. A metodologia Dicumba como uma tempestade de possibilidades para o desenvolvimento do ensino de Química. Revista Brasileira De Ensino De Ciências E Matemática, v. 1, n. 1, 2018a. Disponível em: http://seer.upf.br/index.php/rbecm/article/view/8479/pdf. Acesso em: 15 abr. 2020.

BEDIN, Everton; DEL PINO, José Claudio. Dicumba - o aprender pela pesquisa em sala de aula: os saberes científicos de química no contexto sociocultural do aluno.

Góndola, Enseñanza y Aprendizaje de las Ciencias: Góndola, Ens Aprend Cienc, v. 
13, n. 2, p. 338-352, 2018b. Disponível em:

https://dialnet.unirioja.es/servlet/articulo? codigo=6750774. Acesso em: 18 jun. 2020.

BRASIL. Base Nacional Comum Curricular. Ministério da Educação e Cultura, 2015.

CONSTANTINO, Ana Luiza Alves et al. Pesquisa na Sala de Aula de Química: narrativas das aprendizagens da docência partilhada. Revista Insignare Scientia-RIS, v. 2, n. 2, p. 240-254, 2019. Disponível em:

https://periodicos.uffs.edu.br/index.php/RIS/article/view/10898/7221. Acessado em: 17 jul. 2020.

DEMO, Pedro. Educar pela Pesquisa. Campinas, SP: Autores Associados, 1997.

ENGEL, Guido Irineu. Pesquisa-ação. Educar em Revista, n. 16, p. 181-191, 2000. Disponível em: https://www.scielo.br/pdf/er/n16/n16a13.pdf. Acessado em: 7 jul. 2020.

FRESCHI, Márcio; RAMOS, Maurivan. Unidade de Aprendizagem: um processo em construção que possibilita o trânsito entre senso comum e conhecimento científico. Revista Electrónica de Enseñanza de las Ciencias, v. 8, n. 1, p. 156-170, 2009. Disponível em: http://reec.uvigo.es/volumenes/volumen8/ART9 Vol8 N1.pdf. Acessado em: 10 jul. 2020.

FINGER, Isadora; BEDIN, Everton. A contextualização e seus impactos nos processos de ensino e aprendizagem da ciência química. Revista Brasileira de Ensino de Ciências e Matemática, v. 2, n. 1, p. 8-24, 2019. Disponível em: https://doi.org/10.5335/rbecm.v2i1.9732. Acesso em: 13 jun. 2020.

FREIRE, Paulo. Um sentido para a vida: psicoterapia e humanismo. Tradução Lapenta, V. H. S. 13 ${ }^{\text {a }}$ ed. Aparecida, SP, Editora ideias \& letras, 2005.

GALIAZZI, Maria do Carmo; GARCIA, Fabianne Ávila; LINDEMANN, Renata Hernandez. Construindo caleidoscópios: organizando unidades de aprendizagem. In: MORAES, Roque; MANCUSO, Ronaldo. Educação em Ciências: produção de currículos e formação de professores. Editora Unijuí, p. 65-84, 2004.

KIEREPKA, Janice N.; ZANON, Lenir Basso. Problematização e reconhecimento de teorias e práticas de professores em formação para o ensino de Ciências com foco no educar pela pesquisa. Revista Insignare Scientia-RIS, v. 2, n. 1, p. 1-20, 2019. Disponível em: https://periodicos.uffs.edu.br/index.php/RIS/article/view/10720/7138. Acesso em: 3 jun. 2020

KRAPP, Andreas; HOFER, Manfred; PRELL, Siegfried. Forschungs-Wörterbuch: Grundbegriffe zur Lektüre wissenschaftlicher Texte. Urban \& Schwarzenberg, 1982.

MALDANER, Otavio Aloisio; ZANON, Lenir Basso. Situação de estudo: uma organização do ensino que extrapola a formação disciplinar em ciências. In: MORAES, Roque; MANCUSO, Ronaldo. Educação em Ciências: produção de currículos e formação de professores. Editora Unijuí, p. 43-64, 2004. 
MALDANER, Otávio A. et al. Situação de Estudo como possibilidade concreta de ações coletivas interdisciplinares no ensino médio: ar atmosférico. Encontro nacional de pesquisa em educação em ciências, v. 3, 2001.

MORAES, Roque; GALIAZZI, Maria do Carmo; RAMOS, Maurivan. Pesquisa em sala de aula: fundamentos e pressupostos. MORAES, Roque; LIMA, Valderez. Pesquisa em sala de aula: tendências para a educação em novos tempos. v. 2, (pp. 9-24). EDIPUCRS, 2004.

PIAGET, Jean. A evolução social e a pedagogia nova. In: PIAGET, Jean. Sobre a pedagogia: textos inéditos. São Paulo: Casa do Psicólogo, 1998. p. 97-111.

RANGEL, Fabiano Zolin; BEDIN, Everton; DEL PINO, José Claudio. Dicumba - uma metodologia para o Ensino de Química: avaliação, tendência e perspectiva. In: XII Encontro Nacional de Pesquisa em Educação em Ciências - XIIENPEC Universidade Federal do Rio Grande do Norte, Natal, RN. 2019. Disponível em: http://abrapecnet.org.br/enpec/xii-enpec/anais/resumos/1/R0598-1.pdf. Acesso em: 5 jun. 2020.

ROGERS, Carl Ransom. O poder pessoal (4ª ed.). São Paulo: Martins Fontes, 2001.

SANTOS, Mônica Bertoni. Saberes de uma prática inovadora: Investigação com egressos de um curso de licenciatura Plena em Matemática. 307 f. 2005. Tese de Doutorado. Dissertação (Mestrado em Educação)-Pontifícia Universidade Católica do Rio Grande do Sul, Porto Alegre. Disponível em:

http://tede2.pucrs.br/tede2/handle/tede/3529. Acesso em: 20 jul. 2020.

TRIPP, David. Pesquisa-ação: uma introdução metodológica. Educação e pesquisa, v. 31, n. 3, p. 443-466, 2005. Disponível em:

https://www.scielo.br/pdf/ep/v31n3/a09v31n3.pdf. Acessado em: 24 jul. 2020.

VYGOTSKY, Lev. A formação social da mente: o desenvolvimento dos processos psicológicos superiores. $3^{\mathrm{a} e d}$. São Paulo: Martins Fontes, 1989. 